\title{
E-learning as a Tool for Knowledge Transfer through Traditional and Independent Study at Two United Kingdom Higher Educational Institutions: a case study
}

\author{
JONATHAN D. OWENS \& DAVID FLOYD \\ University of Lincoln, United Kingdom
}

\begin{abstract}
Much has been made of the advances in computer-aided learning activities. Websites, virtual campus, the increased use of WebCT (an online proprietary virtual learning environment system) and chat rooms and further advances in the use of WebCT are becoming more commonplace in United Kingdom universities. However, the effectiveness of these learning methods from the student point of view needs to be questioned. This article looks for ways of changing higher education students' perception of the usefulness of recommended Internet websites for learning purposes, with the intention of increasing the usage rate of recommended module websites. The change could represent an adaptation of the existing, well-known technology to change students' perception regarding its potentially formative role. Subsequently, the outcomes from this preliminary research could be used in order to enhance the quality of Internet use for teaching and learning purposes. The article further draws on secondary sources, including the 2005 Oxford Internet survey that gives constructive perspectives into future policy direction. The article examines some of the learning technologies and introduces the discussion on the evaluation of web-based learning. The research problem that emerges from the discussion is defined and followed by the illustration of the investigative method deployed. The analysis of findings and recommendations conclude the article.
\end{abstract}

\section{Introduction}

Various authors (Kalkota \& Whinston, 1996; Turban et al, 2000; Owens, 2002) have identified that the Internet offers unique opportunities in both teaching and learning applications. Both Ackoff (1989) and Dearing (1997) state that students appear very keen on using the Internet for entertainment, peer communication, and also as secondary source of data. Lissenburgh (1999) claims that in some cases, students assume that the information does not exist if it is not available on the Internet. Although students are familiar with the Internet technology, Gladstone (2000) argues that they quite often tend to lack specific skills that would enable them to use it more effectively.

\section{Learning Technologies}

Research (Gladstone, 2000) suggests that academics seem to have accepted the idea that information technology (IT) can be effectively used for teaching and learning. Students increasingly expect the presence and use of IT in higher education (HE). In some environments the high penetration of IT has become the norm or at least one of the indicators of the quality of a university or a faculty. New students expect the institutions to offer up-to-date IT and Internet access. In line with the recommendations of the Dearing Report (1997), the United Kingdom (UK) universities are investing in IT and accommodating the demand from the majority of students and academics. Some institutions are using IT as a competitive advantage in order to attract more students in the HE market. Increasingly, the students, or should we indeed be calling them 
customers, expect lecturers to use IT for teaching and learning. This is particularly true with mature and distance learning students who are quite often in full-time employment and frequently come from a working environment where IT is an integral part of their working tools. Further evidence (Institute of Teaching and Learning Seminar, 2003) suggests that learning can be enhanced in all sorts of ways: hearing, seeing as well as participating in activities such as a game or quiz.

White (1999) argues that the introduction of IT represents an additional burden on lecturers' timetables since it requires coordination and integration of the activities in the teaching programme. In order to be effective, IT must reflect the current constructivist learning model that over the last few decades has evolved from behaviourist and objectivist models (Fry et al, 1999). Above all, IT-enabled learning must foster interaction and dialogue between the learner(s) and the teacher (Laurillard, 1993).

Laurillard (1994) argues that the potential of learning technologies to improve learning depends on the context of learning. The context is defined by the combination of its elements that include the students, lecturers, institution, teaching material, style and method. Laurillard (1994) also indicates that the majority of studies in this area fail to provide solid evidence of increased effectiveness of IT for teaching and learning. The main common findings appear to indicate that students are enthusiastic about IT and that they take the medium more seriously when their work is assessed. However, IT fails to enable the achievement of significantly different learning outcomes. The studies also suggested that organisational and logistical problems combined with technical difficulties mean that IT cannot be used to its full potential. In order to work better, learning technologies must be fully embedded in a course and the students must be provided with adequate skills and support (Laurillard, 1994; Turban et al, 2000).

\section{An Evaluation of Some of the Learning Technologies Available}

Learning technologies can effectively assist teaching when this is seen as a set of activities aimed at supporting students' learning. This approach corresponds to Level 3 of Biggs's student-centred theory about teaching (Biggs, 1999). Here student learning depends on the student's ability, prior knowledge and accessible new knowledge and on the teaching context, including teacher responsibility, decision making and good management. Therefore, good teaching, including the use of learning technologies, involves an awareness of contextual dependency of learning and teaching (Prosser and Trigwell, 1999)

The evaluation of learning technologies includes the intentions, the implementation process and the outcomes of technology use (Laurillard, 1994). According to Jackson (1998), the purpose of evaluating learning technologies is to provide the designer or user with enough evidence on which to make confident judgements regarding the effectiveness of the innovation. He also claims that the match between the intentions and outcomes determines the success; therefore it is important that the intentions add value to student learning. According to Elkin (2005), success can also lead to further expansion into the international education market where specialist focus on Europe should lead to a niche market for UK and European Union HE providers.

Learning technologies can be evaluated against intended outcomes such as ease of use, efficiency, student preferences, technology attractiveness and cost effectiveness (Jackson, 1998; Gladstone, 2000). The main focus of this article is on student preferences, with some inevitable overlaps with the areas of technology attractiveness and efficiency.

\section{Evidence of Internet Use}

According to the Oxford Internet 2005 survey, $92 \%$ of people go online to check emails, $74 \%$ buy online, $43 \%$ play games and $42 \%$ look for jobs, whereas currently only $21 \%$ use it for distance learning purposes. Even downloading to watch videos and listen to the radio achieved an almost $10 \%$ better score than distance learning. There has also been a fall in people developing websites and using the Internet for creative purposes. Equally disappointing for learning purposes is that $20 \%$ read less due to the advent of the Internet, thus indicating the need for lecturers to realise that the Internet is not a perfect substitute for knowledge and that both means need to be encouraged 
to foster more creativity. A summary of the 20 main reasons why people access the Internet is illustrated in Figure 1.

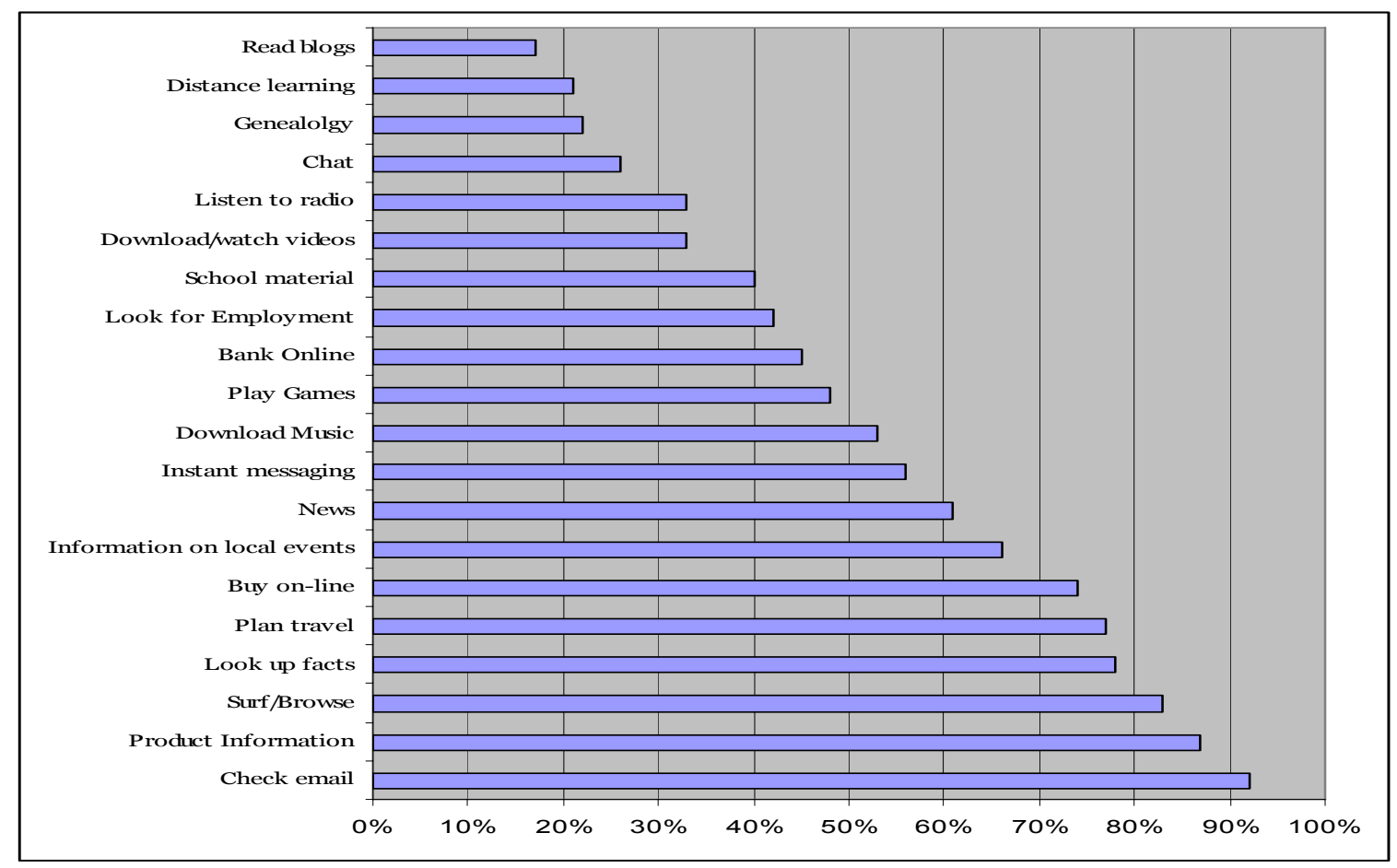

Figure 1. Twenty fundamental reasons why we go online (Oxford Internet Survey, 2005).

\section{Knowledge - the basic perception}

It is apparent from the literature on knowledge management $(\mathrm{KM})$ that there is much debate about what constitutes knowledge, what is data and what is information. Subsequently, with the increased interest in knowledge that cannot be captured, various researchers (Ackoff, 1989; Nonanka \& Takeuchi, 1995; Gladstone, 2000; Na Ubon \& Kimble, 2002) have begun to realise that the management of knowledge poses significant challenges. This has led to much debate about how to describe and theorise about such knowledge. Subsequently, different KM researchers and practitioners have used different terms to distinguish between the types of knowledge of interest to $\mathrm{KM}$ and knowledge transfer (KT). Almost all these views tend to see knowledge as a dichotomy (Ackoff, 1989; Conkin, 1996; Blackler et al, 1998; Nonanka et al, 2000; Na Ubon \& Kimble, 2002).

\section{Knowledge Management}

Knowledge management $(\mathrm{KM})$ is used to describe everything from the application of new technology to the harnessing of the intellectual capital of an organisation (Sallis \& Jones, 2002). Rasmussen (2000) claims that KM originates from the recognition that the dimensions of competition have noticeably changed from the dependence on natural resources to the competition for intellectual resources. McElvily et al (2000) attempt to define KM as the systematic management of the knowledge process by which knowledge is identified, gathered, shared and applied. An earlier study by Argyris (1993) claims it to be the systematic and organised attempt to use knowledge within an organisation to improve performance.

In summary, $\mathrm{KM}$ can be considered as the management of processes that govern the creation, dissemination and utilisation of knowledge by merging technologies, organisational structures and people to create the most effective learning, problem solving and decision making within an organisation. 


\section{Knowledge Transfer}

Various researchers (Stewart, 1977; Ratcliffe, 1997; Hall \& Bannatyne, 1999; Jackson; 2002) over the years have taken the common view that $\mathrm{KM}$ is often used to describe the management of knowledge within the organisation, and this includes knowledge transfer (KT) within the organisation.

Bates (2001) claims that the value of KM relates directly to the effectiveness with which the transferred knowledge enables educators within the establishment to deal with the current situations and effectively envision and create their future. People are the most critical factor in KM. People create knowledge, share knowledge, learn and use knowledge to complete tasks. KT increases the ability of individuals to deal with new situations, events, information and context. Many barriers to effective KT emerge because the process relies heavily on human interactions and relationships that are not designed into the establishment's culture

\section{Knowledge Transfer Using E-learning}

E-learning can be perceived as a key enabler to KM and KT within HE sector (Owens, 2002).

The successful introduction and implementation of e-learning into existing and new units at higher education institutions (HEIs) can be heavily influenced by the institution's ability and effectiveness in delivering knowledge-based products and managing any number of strategic issues that may need to be addressed as part of the successful development of KT though e-learning products.

The strategic issues of significance when considering e-learning as a tool for KT through traditional and independent study within the HE sector are:

- identifying the customer service imperative for each stakeholder or institute involved in an elearning initiative;

- appreciating the advantages and disadvantages of incremental KT through e-learning in HE;

- understanding the value of national, integrated approaches to e-learning and KT in HE;

- understanding the need to develop user support systems, to underpin e-learning and KT developments;

- working within technological and financial limitations associated with HEIs;

- successful internationalisation of university education.

\section{Methodology}

The fieldwork for this research took place at two UK HEIs; Lincoln Business School (LBS), University of Lincoln and Buckinghamshire Business School (BBS), Buckinghamshire Chilterns University College. A number of units that include IT-based learning were identified. Three units presented some interesting sets of characteristics and subsequently were selected for this study. The cohort for this study included both undergraduate and postgraduate students studying fulltime at both HEIs and it offers an interesting platform for discussion. Furthermore, the students present some similarities that were considered important in the attempt to keep control over a number of variables. All units include a website that is aimed at supporting students' learning. The site gave the lecturer some degree of flexibility in terms of inclusion of teaching material and setting up the discussions despite being fairly standardised.

The fieldwork included an unstructured interview/discussion with the lecturer and a questionnaire. The discussion with the lecturer was aimed at identifying the main issues relative to the use of the website that emerged during the semester and this formed the basis for the questionnaire. The respondents' breakdown for each module at both HEIs is illustrated in Table I. 


\begin{tabular}{|c|c|c|c|c|c|}
\hline \multicolumn{3}{|c|}{ Lincoln Business School } & \multicolumn{3}{|c|}{ Buckinghamshire Business School } \\
\hline Module & Level & $\begin{array}{l}\text { Number of } \\
\text { respondents }\end{array}$ & Module & Level & $\begin{array}{l}\text { Number of } \\
\text { respondents }\end{array}$ \\
\hline Operations & CMS & 17 & Operations & CMS & 12 \\
\hline Management & & & Management & & \\
\hline Strategic & BA 3 & 14 & Strategic & BA 3 & 17 \\
\hline Management & & & Management & & \\
\hline $\begin{array}{l}\text { Management of } \\
\text { Operations }\end{array}$ & BA 2 & 19 & $\begin{array}{l}\text { Management of } \\
\text { Operations }\end{array}$ & BA 2 & 13 \\
\hline & & Total: 50 & & & Total : 42 \\
\hline
\end{tabular}

Table I. Respondents breakdown from both HEIs.

\section{Findings}

Interview

From each interview with the lecturer held at both institutes it emerged that the publisher of each unit's core text provided a website that was aimed at offering additional support for the students. Although standardised to some extent, the website offers a certain degree of flexibility. The lecturer was able to publish the lecture notes, the syllabus, the module outline, the assessment brief and any other text material. The related web links could be edited at the discretion of the lecturer who has control over the content of the website. Additionally, the lecturer can set up the discussion area by proposing a topic and encouraging student participation. Typically, the lecturer was posting a question that was related to the lecture on weekly basis. The students could respond or comment on the topic and get the lecturer's feedback. The students could see the contributions of their colleagues but could not address the comment to one particular colleague. The communication channel corresponded to the interactive one-to-many model. Each participant was identified through a username and a password.

The discussion with the lecturer also allowed for identification of the main themes and items, which were then included in the questionnaire. The lecturer reviewed the draft questionnaire and administered the final version to the students during one of the last sessions in semester one.

\section{Questionnaires}

The following results combine the findings at both LBS and BBS across all levels investigated.

Feedback from Certificate in Management Studies (CMS) for the Operations Management module at LBS and $B B S$. These students scored the lowest usage rate of the three groups surveyed. It was established that only $21 \%$ of respondents at LBS and $19 \%$ of respondents at BBS log on the website at least once a week, and that approximately two-thirds of the students at the two institutions visit the website once per month or less, which means not more than five times in a semester.

When the students log on they mostly look at the lecturer's questions but only one in four contributes to the discussion. A common characteristic between the two institutions was that approximately two-thirds look at the contributions of other students and use the web links. Less than half use the web-based lecture notes and less than a third use other material related to the assessment.

From feedback at both institutions it was established that the majority feel that the website helps their learning, makes it easier to keep up to date with the lectures, offers the opportunity to discuss topics with the lecturer, and gives them the opportunity to ask for clarifications. However, a large majority at both institutions do not think that the website gives either the lecturer a tool to monitor their learning or themselves the opportunity to show how much they study. Interestingly, a large number of students at both institutions would like to see the web-based work as part of their portfolio of activities; however, less than a third would like this work to be assessed.

Another common finding from both institutions was that the vast majority would like the website to contain more assessment/learning-related material. Approximately half of the 
respondents would like it to be more enjoyable to use, to count towards the final mark, and to be assessed on a pass/fail basis.

The students at both institutions indicated that they would prefer the website to be an addition to the seminars and that they would like to see it part of their assessment. There were a number of positive comments from people who were in general quite satisfied with the website and its functions.

Feedback from the BA 3 Strategic Management module at LBS and BBS. It was established that almost two-thirds of the students at each institution visit the website at least every other week. They predominantly use the lecture notes, look at the lecturer's questions, and at the contributions from other students. However, only $17 \%$ at LBS and $14 \%$ at BBS have ever contributed to the discussion on the website.

Similar to earlier findings with the CMS cohort, the students at both institutions were in agreement that the website helps their learning, makes easier to keep up to date with the lectures, offers the opportunity to discuss topics with the lecturer, and gives them the opportunity to ask for clarifications. However, the majority of students studying this module at both institutions agree that web-based work should not be assessed for this module at this level. Approximately one in four at LBS and one in three at BBS agree that it should be part of the portfolio of activities.

Another common finding between both institutions was that only a small minority would use it more if it were assessed on pass/fail basis, but almost two-thirds would use it more if it counted towards their final mark. However, the vast majority of students at both institutions were of the opinion that they would use it more often if there was more material related to the module assessment.

Feedback from the BA 2 Management of Operations module at LBS and BBS. It was both an interesting and common finding at both institutions that almost half (49\% LBS and $47 \%$ BBS) of the students use the website on a weekly basis. This was perhaps a more feasible and perhaps more expected finding at level three and postgraduate, rather than at level 2.

Similar to the previous two cohorts at both institutions, these students mostly use the lecture notes; they look at the lecturer's questions and use the web links. A common finding between the two institutions was that approximately half of the respondents think that the website helps their learning and that it makes easier to keep up to date with the lectures. A noticeable difference between the two institutions was that approximately one in three at LBS and only one in four at BBS thought that it offered them the opportunity to discuss with the lecturer, gave the opportunity to ask questions and to show how much they study, and that it should be part of the portfolio. However, only one in four at both institutions thought it should be assessed.

The students at both institutions were of the opinion they would use the website more often if it counted towards the final mark, if there was additional learning material and if there was more material related to the assessment.

Another common finding was that the lecturer should promote the website more convincingly during the lectures and seminars. It should also be easier to use and it should be part of the portfolio of activities.

\section{Discussion}

Generic

All the respondents were aware of the website and have logged on at least once. Although they seem generally happy with the site they made limited use of it mainly because it is not assessed in any way. They suggest including the web-based work in the portfolio of activities and making it count toward their final mark. They are not, however, supportive of the idea of the work being directly assessed. They mostly use the lecture notes and other material. In general, they were not entirely enthusiastic about contributing to the online discussion initiated by the lecturer. One motive for that outcome could be the purpose of having to undertake further work beyond what was necessary/required for each unit, although there was a strong indication of their preference for assessed work. Essentially, they were of the opinion that they were only prepared to undertake 
work that they would be rewarded for. However, it should be understood that this is part of human nature and that the students would not do anything unless they clearly benefited, by way of it contributing toward their grade. Certainly, it remains debatable how to move the perceived added value of any work away from the assessment. The students are prepared to undertake nonassessed work if they can distinguish it as valuable for their progress and perhaps future assessment and/or grade. It was evident that the web-based work should be included in the portfolio of activities and be assessed perhaps on a pass/fail basis.

\section{Findings}

An encouraging finding (for academics) was that the vast majority of students feel that the website does not make it less necessary to attend the lectures. The supporters of computer-enabled learning will argue that the website has to be structured in a different way in order to enable the development of a fully suitable learning environment. However, none of the respondents indicated that the website should ultimately serve as a substitute for lectures. Evidence indicated quite the opposite; a general consensus was to keep the seminars and increase the contact time with the lecturer.

\section{Improvement}

The majority of respondents across both institutions would like to see more teaching material and more material related to their assessment. They would also use the website more often if it counted towards their final mark. These findings are similar to those of Laurillard (1994), discussed earlier in this article. Assessment could consist of a small component of the unit's total marks to start with. Multiple-choice tests have been used for this purpose and the technology allows for a speedy process of marking assessment. However, there are limitations to going further at present. Audio technology now being developed may raise the problem of disturbing fellow students during the assessment. It is also proving more difficult to use technology that adds to creativity skills and it is unlikely that at present these skills can be tested effectively electronically so long as people view the Internet only as an information source.

\section{Differences}

The main differences that were common between each institution were:

- a more strategic approach of the CMS students that called for more material;

- the BA level 3 students' were more preoccupied by the assessment and called for more clarity and ease of use;

- the BA level 2 students scored lowest for the alleged benefits of the website. They thought the web-related work should be encouraged more during the lectures, thus facilitating their learning toward the assessment.

\section{Conclusions and Recommendations}

The numerous positive comments from this research were encouraging for the development of the web-based learning environment. The respondents appeared to enjoy it and were motivated to use this new learning medium. The lecturers should use this opportunity and encourage students' participation in web discussions. However, secondary sources have shown that the Internet has led to less use of books in the learning process. Both Internet use and reading books need to be encouraged in order to improve creativity. The contributions of Internet learning should therefore count towards the completion of only part of the module. The most appropriate form of assessment seems to be the portfolio of activities to be assessed on a pass/fail basis. In other words, it should form a compulsory part of activities to pass the module but the assessment should not contribute to the final mark. This needs only to be a limited part of the assessment since as it has been shown in this article that Internet learning does not always foster the most creative elements of the learning process at present. 
The literature presents an increasing number of studies that include both examples of good practice and cases of failure. This is further supported by mixed evidence claiming greater Internet use but not for creative purposes according to the Oxford 2005 Internet Survey. However, more research is needed in order to build models of computer-enabled learning activities because the contextual characteristics are still determining the outcome of various initiatives. It has also been observed that six out of ten adults now use the Internet. However, younger people tend to be more familiar with the technology; further work could, for example, classify the student sample in terms of age groupings.

People are the most critical factor in KT. People create knowledge, share knowledge, learn, and use knowledge to complete tasks. Knowledge sharing increases the ability of individuals to deal with new situations, events, information and context. Many barriers to knowledge sharing occur because the process relies heavily on human interactions and relationships that are not designed into the establishment's culture. Institutions must create, promote and foster a knowledge-sharing environment to replace the culture of hoarding information. Individuals must be developed and nurtured through strategic initiatives.

\section{Future Policy Directions}

It has been encouraging to see an increase in use of the Internet and awareness of what can be offered in terms of learning technologies. Technology has also improved in terms of reliability and the range of services that can be offered. Evidence in the USA has shown students to prefer the more traditional means of teaching and communications where possible as most traditionally based courses fill up first and online programmes may still be seen as second best. However, the number of distance learners is increasing and in some circumstances this can provide a close substitute to traditional methods. There is also the benefit of increased flexibility in the provision. A mix of provision in the assessment strategy, as this article advocates, may prove to be the best approach in the future in order to motivate students to achieve the best of their ability.

The final comment is to reiterate and encourage the sharing of experiences in an area of teaching and learning that is assuming a very important and strategic role in higher education.

\section{References}

Ackoff, R.L. (1989) From Data to Wisdom, Journal of Applied Systems Analysis, 16, 20-37.

Argyris, C. (1993) Knowledge for Action: a guide to overcoming barriers to organisational change. San Francisco: Jossey-Bass.

Bates, T. (2001) National Strategies for E-learning in Post Secondary Education and Training. Paris: UNESCO.

Biggs, J. (1999) Teaching for Quality Learning at University. Buckingham: Open University Press.

Blackler, F., Crump, N. \& McDonald, S. (1998) Knowledge Organisation and Competition, in G. von Krogh, J. Roos \& D. Kleine (Eds) Knowing in Firms, 67-86. London: Sage.

Conkin, E.J. (1996) Designing Organisational Memory: preserving intellectual assets in a knowledge economy. Glebe Creek, MD: CogNexus Institute. http: / / cognexus.org/ dom.pdt

Dearing, R. (1997) Higher Education in the Learning Society. Report to the National Committee of Inquiry into Higher Education. Norwich: HMSO.

Elkin, G. (2005) Visualising the Internationalisation of Universities, International Journal of Educational Management, 19(4). http: / / dx.doi.org/10.1108/09513540510599644

Fry, H., Ketteridge, S. \& Marshall, S. (1999) Understanding Student Learning, in H. Fry, S. Ketteridge \& S. Marshall (Eds) A Handbook for Teaching and Learning in Higher Education. London: Kogan Page.

Gladstone, B. (2000) From Know-How to Knowledge. London: The Industrial Society.

Hall, R.A. \& Bannatyne, M.W. (1999) Technology Education and the 21st Century, Connect, 24(4), 1-3.

Institute of Teaching and Learning in Higher Education Conference (2003) Institute of Teaching and Learning Seminar, University of Central England, January.

Jackson, B. (1998) Evaluation of Learning Technology Implementation, in N. Mogey (Ed.) Evaluation Studies, 22-25. Edinburgh: Learning technology dissemination initiative.

Jackson, T. (2002) International HRM - a cross-cultural approach. London: Sage. 
Kalkota, R. \& Whinston, A.B. (1996) Frontiers of Electronic Commerce. Reading, MA: Addison Wesley.

Laurillard, D. (1993) Rethinking University Teaching: a framework for the effective use of educational technology. London: Routledge.

Laurillard, D.M. (1994) How Can Learning Technologies Improve Learning? Law Technology Journal, 3(2), 30-47.

Lissenburgh, S. (1999) Knowledge Links, New Economy, 6(1), 28-32.

McElvily, S.K., Das, S. \& McCabe, K. (2000) Avoiding Competence Substitution through Knowledge Sharing, Academy of Management Review, 25(2), 294-331. http: / / dx.doi.org/10.2307/259015

Na Ubon, A. \& Kimble, C. (March 2002) Knowledge Management in Online Distance Education. 3rd International Conference Networked Learning Proceedings, 465-473. Sheffield: University of Sheffield.

Nonanka, I. \& Takeuchi, H. (1995) The Knowledge Creating Company: how Japanese companies create the dynamics of innovation. New York: Oxford University Press.

Nonanka, I., Von Krogh, G. \& Ichijo, K. (2000) Enabling Knowledge Creation. New York: Oxford University Press.

Owens, J. (2002) E-Quality: a knowledge management (KM) based framework for e-business-learning (EBL) at higher educational business institutes (HEBI), Manufacturing Engineering Journal, 84(3), 196-200.

Oxford Internet Survey (2005) Oxford Internet Survey 2005 by Oxford Internet Institute (OII). http: / /www.oii.ox.ac.uk

Prosser, M. \& Trigwell, K. (1999) Understanding Learning and Teaching: the experience in higher education. Buckingham: Open University Press.

Rasmussen, K. (2000) Knowledge Management in Multinational Companies: the use of shared space in crosscultured settings. Unpublished Working Paper. Copenhagen: Copenhagen Business School.

Ratcliffe, P. (1997) A Theoretical Framework for the Study of Knowledge Transfer in Organisations. First International Organisation Conference, Warwick Business School, Warwick University.

Sallis, E. \& Jones, G. (2002) Knowledge Management in Education. London: Kogan Page.

Stewart, T.A. (1977) Intellectual Capital - the new wealth of organisations. London: Nicholas Brealey Publishing.

Turban, E., Lee, J., King, D. \& Chung, H.M. (2000) Electronic Commerce: a managerial perspective. London: Prentice-Hall.

White, S. (1999) Using Information Technology for Teaching and Learning, in H. Fry, S. Ketteridge \& S. Marshall (Eds) A Handbook for Teaching and Learning in Higher Education. London: Kogan Page.

JONATHAN D. OWENS in a Senior Lecturer in Operations Management in the Lincoln Business School at the University of Lincoln, United Kingdom. His research interests are knowledge transfer through distance learning, in particular in the field of logistics management. He is a Chartered Engineer and currently a member of the Chartered Institute of Purchasing and Supply (CIPS) logistics forum with 14 other UK universities discussing benefits of e-learning and knowledge transfer in the field of logistics. His other areas of interest are the learning issues to be understood in the design process, in particular the NPD process and new product development issues and the appreciation of having a structure technology road map incorporated into the process. Correspondence: Jonathan D. Owens, Lincoln Business School, University of Lincoln, Brayford Pool, Lincoln LN6 7TS, United Kingdom (jowens@lincoln.ac.uk).

DAVID FLOYD in a Senior Lecturer in International Business in the Lincoln Business School at the University of Lincoln, United Kingdom. His research interests are knowledge transfer through distance learning, in particular in the field of international business. His other interests are in economics and the business environment. Correspondence: David Floyd, Lincoln Business School, University of Lincoln, Brayford Pool, Lincoln LN6 7TS, United Kingdom (dfloyd@lincoln.ac.uk). 